Egyptian J. of Nutrition Vol. XXXIII No. 3 (2018)

\title{
Sources of dietary sodium among Egyptian adults.
}

\author{
*Sahar S. Zaghloul ** Ashraf A. Abd-El Mogeid *Asmaa \\ S. Abd ElAal, *Naglaa M. Abd El Fattah, \\ *The National Nutrition Institute \\ ${ }^{\star *}$ The Faculty of Home Economics- Helwan University
}

\begin{abstract}
To determine food sources of sodium among Egyptian adults, 96 healthy adults aged 25-64 years were selected from workers of the National research institutes of the General Organization of Teaching Hospitals and Institutes (GOTHI). Two 24-hour dietary recalls were collected using the United State Department of Agriculture's (USDA) multi-pass method between 2014 and 2016. In addition socioeconomic information were collected. Weight and height were measured.

Results showed that: The mean sodium intake was $3841.4 \pm 1223.7$ for males and $2735.0 \pm 1118.9 \mathrm{mg} / \mathrm{d}$ for females. The major food items rich in sodium were baladi bread $(15.1 \%)$ and white cheese $(10.9 \%)$. The top food groups contributing to sodium intake were composite dishes/homemade food $(26.1 \%)$, bakeries $(23.6 \%)$, dairy $(20.0 \%)$ and fast food $(8.3 \%)$. (40.1\%) of sodium was consumed in lunch, followed by breakfast $(29.3 \%)$ then dinner $(23.7 \%)$.
\end{abstract}




\section{Sahar S. Zaghloul Ashraf A. Abd-El Mogeid \\ Asmaa S. Abd ElAal, Naglaa M. Abd El Fattah,}

\section{Introduction}

Although sodium is an essential nutrient for human health with important role in balancing electrolytes and osmotic solutes (Strazzullo and Leclercq, 2014) excessive salt consumption may increase the risk of cardiovascular diseases through increase hypertension. A reduction in sodium intake by $1,000 \mathrm{mg}$ per day reduced hypertension by $2.7 / 1.1 \mathrm{mmHg}$, stroke death by $42 \%$, and death from coronary heart disease by reduced $40 \%$ (He et al, 2014). In adults and children with no acute illness, a decrease in the intake of sodium from the typical high levels reduces blood pressure (Gradual et al., 2011). A low sodium diet results in a greater improvement in blood pressure in people with hypertension (Adler et al., 2014).

The World Health Organization recommends that adults should consume less than $2,000 \mathrm{mg}$ of sodium, equivalent to 5 grams of salt per day (WHO, 2014). Dietary sodium intake is recommended by the American Heart Association (AHA) to be $<1,500 \mathrm{mg}$ daily (Whelton et al., 2012, 10M, 2013).

Associations and experts in developed countries have being working to identify dietary sources of sodium and to reduce its consumption or reduce salt in processed food (Kochanek et al., 2011; European Food Safety Authority, 2016). In the United States, $75 \%$ of the sodium eaten comes from processed and restaurant foods, $11 \%$ from cooking and table use and the rest from what is found naturally in foodstuff (He et al. , 2013). The high 
level of sodium in many processed foods has a major impact on the total amount consumed (Mattes and Donnelly, 1991.). Typically sources of sodium include natural sources, processed foods, condiments, salt added while cooking or salt added at the table (He et al., 2013).

However in the Middle East and North Africa (MENA) region limited data exist on dietary salt intake. To our knowledge sources of salt in Egyptian diet is not available. The aim of the present study is to identify main sources of salt in Egyptian adult's food intake.

\section{Material and Method}

Ninety six participants were recruited from employees of the General Organization of Teaching Hospital and Institutes (GOTHI) located in Kasr E| Aini Street. Adults between 25-64years of age with no history of cardiovascular, liver or kidney failure were included in the cross-sectional study. The study was approved by Ethic committee of GOTHI.

\section{Data collected}

Demographic and socioeconomic data including age, gender were collected. WHO anthropometric measurement protocol was used to obtain weight and height. BMI was calculated as the weight in $\mathrm{kg}$ divided by the height square in meters (WHO, 1995). Two 24-hr dietary recalls were collected from each subject using the Multiple Pass Food Recall (MPR) method which is a 5step approach, developed by the United State Department of 


\section{Sahar S. Zaghloul Ashraf A. Abd-El Mogeid Asmaa S. Abd ElAal, Naglaa M. Abd El Fattah,}

Agriculture (USDA) (Moshfegh et al., 2008). Well trained dieticians collected the food and drinks consumed in the last 24 hours and portions were determined using local cups and plates. The questionnaires were reviewed and edited by senior dieticians Composite dishes and homemade food recipes were collected when permissible and amount consumed by the participant was estimated. Nutrients analysis was performed using ESHA Research Food Processor SQL and ESHA Port SQL software version 10.3. The ESHA Food Processor software was updated to incorporate Egypt Food Composition table (Eid, 2006). In case of missing food item, the collected recipe was entered.

Food was grouped into 17 food groups bakeries, fruits fresh and juices, beef, fish, chicken, dairy, eggs, pickles, processed food, legumes and seeds, fresh vegetables, drinks, fast food or food consumed away from home, desserts and sweets, soups, spices and composite dishes. The Australia and New Zealand food grouping system was adapted (AUSNUT, 2015). However modifications were done targeting sodium sources in Egyptian culture where cold cuts (pastrami, luncheon meat and sausages) were considered as processed food rather than in the meat group as in the AUSNUT classification. Also sandwiches not prepared at home were added to a new food group called fast food (away from home).

Pickles a traditional Egyptian food habit was separated from condiments, sauces group. Composite dishes were also separated to target homemade foods and food was considered 
composite dish if contains food from more than three food groups examples included stuffed vegetables eggplants, stuffed vine leaves, koshari, rukak, cooked potatoes, cooked beans with meat. If koshari was consumed away from home, it was included in the fast food/ away from home group. Processed food included canned food (tuna, sardine, fava beans (Foul), as well as cold cuts (Bastrami, sausage, luncheon meats, etc.) Bakeries included bread, bread stick, biscuits, and fiteer. Fast food/away from home group included sandwiches foul, falafel, liver, fried eggpiant, fried potatoes, pizza etc. Legume and seeds group included foul (fava beans), black eye beans, kidney beans, chickpeas, lentils as well as salted pumpkin seeds, watermelon seeds and lupines. Beef, chicken and fish groups included grilled, baked or boiled dishes.

\section{Statistical analysis}

Statistical analyses were performed using SPSS version 21 (IBM Corp. Released 2012. IBM SPSS Statistics for Windows, Version 21.0. Armonk, NY: IBM Corp.). Sodium contents of each food as well as within each food group was estimated and percent of total sodium intake was calculated. Descriptive statistics were used to describe food group contributions to total sodium intake. Mean contributions and SD for the sample, and the percentage of sodium obtained from food items and each food group were calculated. Analysis of variance (ANOVA) and Student's t-test were used to assess the differences in the mean sodium intake between different socioeconomic variables. A $p$ value of $<0.05$ was considered significant. 
Sahar S. Zaghloul Ashraf A. Abd-El Mogeid

Asmaa S. Abd ElAal, Naglaa M. Abd El Fattah,

\section{Results}

Table 1 shows the mean sodium intake $(\mathrm{mg})$ by sample characteristics. The mean sodium intake was significantly different between males $(3841.4 \pm 1223.7)$ and females $(2735.0 \pm 1118.9$ $\mathrm{mg}$ ) with $p=0.00$. Single subjects had higher sodium intake compared to married and divorced subjects $(3529.1 \pm 1667.8$, $3174.9 \pm 1269.1$ and $3065.9 \pm 714.8 \mathrm{mg}$ respectively) in spite of not reaching statistical significant. Similar pattern of sodium intake was noticed among subjects older than 45 years of age (3258.1 \pm 1243.5), with family size more than $5(3314.1 \pm 1290.0)$ and with poor economic status $(3327.7 \pm 920.8)$. Unexpectedly subjects with higher income consumed more sodium (3454.2 \pm 1651.8$)$ and obese subjects consumed less sodium compared to normal BMI and overweight subjects $(3091.0 \pm 1360.5,3302.8 \pm 1042.0$ and $3399.1 \pm 1253.3 \mathrm{mg}$ respectively).

Figure 1 shows the top food items contributing to sodium intake $(>1 \%)$. Baladi bread contributed $15.1 \%$ of the total sodium intake followed by white cheese $(10.9 \%)$. Mish/kareesh cheese contributed around (3.3)\% followed by pickles (3.2\%) and cooked rice fried with noodles $(3 \%)$.

Salt added while cooking accounted for $3.2 \%$ of total sodium intake however it is important to note that this salt represent only salt used in collected recipes not of all composite/homemade dishes. 


\section{Egyptian J. of Nutrition Vol. XXXIII No. 3 (2018)}

Figure 2 shows that almost one quarter of salt came from composite or homemade dishes $(26.1 \%)$ followed by grain products $(23.6 \%)$ followed by milk, yogurt and cheese $(20 \%)$. Food consumed away from home/fast food contributed $8.3 \%$ and pickles $(4.7 \%)$.

Table 2 presents mean sodium consumed by meal. Subjects consumed $2726.4 \pm 1406.9 \mathrm{mg}$ sodium in lunch followed by $1987.1 \pm 251.1 \mathrm{mg}$ in breakfast. Distribution of sodium intake by meal (Figure 3 ) showed that lunch contributed $40.1 \%$ of total sodium intake followed by breakfast $29.3 \%$ then dinner $23.7 \%$.

\section{Discussion}

The present study showed most Egyptian subjects did not adhere to the WHO guidelines for sodium intake (2000 $\mathrm{mg}$ per day) and that men consumed more than women. Baladi bread and cheese were main food items contributing to sodium intake. While among the food group, composite dishes/ home prepared food was the richest sodium source in Egyptian diet followed by grain group including baladi bread and other bakeries. Almost one fourth of the sodium came from bread and other bakeries. Therefore urgent action is required given that $80 \%$ of non-communicable disease (NCD) deaths occur in Low middle income countries (LMICs)and the greatest increase of NCD is projected to be in South East Asia and the Eastern Mediterranean (WHO, 2014).

These findings are in consensus with reports from many countries where bread contributed $19 \%$ and cereals group 


\section{Sahar S. Zaghloul Ashraf A. Abd-El Mogeid Asmaa S. Abd ElAal, Naglaa M. Abd El Fattah,}

contributed $32.5 \%$ (Keogh, et al,.2013) and $27 \%$ from bread and cereal group combined in Australia(Chariton et al., 2010), 25.7\% from bread in New Zealand (Russell et al., 1999). On the other hand Margerison et al. (2004) reported that bread contributed only $8 \%$ of the sodium intake of the Australian participants.

Comparing non-processed to processed/ commercial foods, breads/cereals/grains contributed $95 \%$ of total sodium intake in the United Kingdom, (Anderson et al., 2010).13.9\% in Canada (Fisher et al., 2009), 34\% in Turkey (Erdem et al., 2017) and 26\% in Lebanon (Al Medawar et al., 2105).

Other processed foods with high density of sodium were processed meats $8.90 \%$ and pasta dishes $5.67 \%$. in the UK, processed meats $(10.3 \%)$, sauces $(6.7 \%)$, potatoes and kumara $(6.7 \%)$ breakfast cereals $(5.8 \%)$ in Canada (Russell et al, 1999) and processed meat (12\%), and dairy products $(9 \%)$ in Lebanon (Al Medawar, et al., 2015).The current study however identified dairy products mainly white cheese as highest source of sodium (20\%) from commercial products after bread and bakeries.

In Western countries generally three-quarters of sodium consumed is obtained from salt added during food manufacture, with the remainder either added at the table or in cooking (discretionary salt), or naturally present in food (James, et al., 1987, Mattes and Donnelly, 1991). On the contrary, Asian countries China, Japan and Korea reported around $75 \%$ of sodium came from homemade meals or salt added during cooking with $8 \%$ 
Egyptian J. of Nutrition Vol. XXXIII No. 3 (2018)

from soy sauce in China and Japan and $25 \%$ from kimchi in Korea(Zhao et al., 2004; and Anderson et al., 2010;Song et al., 2013). The current study reported $26 \%$ of sodium came from food cooked at home and extra 3.2\% from added recipes missing in the food composition database which is less than the $75 \%$ reported from Asian countries but close to the 30\% reported from Turkey (Erdem et al., 2017).

Our study showed no difference in salt intake by education, economic status, age or marital status. Only sodium intake significantly differed by gender. This finding indicates the need for a community based or system level intervention working with food producers to reduce salt in food processing or increase production of low salt products in combination with nutrition education targeting food prepares mainly women to replace salt with herbs and other spices. Hasenegger et al., (2018) studied adult Australians between 18-64 years of age found similar results where salt intake did not differ by affluence, educational level, smoking status and physical activity. Salt intake differed by gender and increased with increase in BMI which was inconsistent with our previous work (Abd ElAaL et al., 2018) which showed no difference with increase BMI.

Results of this study identified lunch $(40.1 \%)$ as the meal with highest salt intake followed by breakfast $(29.3 \%)$ then dinner $(23.7 \%)$. We can speculate that high sodium in lunch was due mainly to home cooking while breakfast was due to fast food or food consumed away from home which included sandwiches such as foul (fava beans), falafel and fried eggplants and potatoes, traditional breakfast for working force in Egypt. Khan (1983) 


\section{Sahar S. Zaghloul Ashraf A. Abd-El Mogeid}

Asmaa S. Abd ElAal, Naglaa M. Abd El Fattah,

investigated the total sodium intake from meals and snacks consumed by selected college students. Most students used carbonated beverages, candies, gums, cookies, and salted snack items. Sodium intake was greater from regular meals than from snack foods. Salted snack items were consumed mostly as evening snacks. However, in Korean young adults aged 20-26 years, using a 125-item dish-frequency questionnaire Shim et al. (2013) found that salt intake was increased with increased number of meals and was reduced with increased number of snacks. Also evening snacks had more salt than morning snacks.

The limitations of the current study include small sample size and recruitment of governmental employees which limit generalization of the findings. In addition, lack of information on salt added on the table may indicate underestimation of salt consumed.

Conclusions: Over consumption of sodium requires immediate intervention to reduce dietary sodium among Egyptian adults. Focus on limiting sodium in commercial bakeries mainly baladi bread production, substituting salt while cooking with more herbs and making low salt dairy products mainly cheese more available and affordable are suggested strategies for salt reduction 
Egyptian J. of Nutrition Vol. XXXIII No. 3 (2018)

Table1: Mean \pm SD sodium intake $(\mathrm{mg})$ by characteristics of the sample

\begin{tabular}{|c|c|c|c|c|}
\hline Characteristics & & $N$ & Mean + SD & $\begin{array}{c}P- \\
\text { value }\end{array}$ \\
\hline \multirow{2}{*}{ Gender } & Males & 41 & $3841.4+1223.7$ & \multirow[t]{2}{*}{0.000} \\
\hline & Females & 55 & $2735.0+1118.9$ & \\
\hline \multirow{3}{*}{ Marital status } & Single & 11 & $3529.1+1667.8$ & \multirow[t]{3}{*}{0.7} \\
\hline & Married & 78 & $3174.9+1269.1$ & \\
\hline & Divorced & 7 & $3065.9+714.8$ & \\
\hline \multirow{4}{*}{ Social score categories } & Very low & 21 & $3274.7+1261.8$ & \multirow[t]{4}{*}{0.7} \\
\hline & Low & 25 & $3046.0+1225.9$ & \\
\hline & Middle & 25 & $3448.4+1354.6$ & \\
\hline & High & 25 & $3071.8+1317.3$ & \\
\hline \multirow{3}{*}{ BMl category } & Normal & 15 & $3302.8+1042.0$ & \multirow[t]{3}{*}{0.6} \\
\hline & Overweight & 26 & $3399.1+1253.3$ & \\
\hline & Obese & 55 & $3091.0+1360.5$ & \\
\hline \multirow{2}{*}{ Age group } & $<45$ years & 50 & $3161.1+1328.2$ & \multirow[t]{2}{*}{0.7} \\
\hline & $=>45$ years & 46 & $3258.1+1243.5$ & \\
\hline \multirow{2}{*}{ Family size } & $-<5$ & 27 & $2935.3+1245.3$ & \multirow[t]{2}{*}{0.2} \\
\hline & $>5$ & 69 & $3314.1+1290.0$ & \\
\hline \multirow{3}{*}{ Income } & $<2000 \mathrm{LE}$ & 39 & $3091.7+1271.1$ & \multirow[t]{3}{*}{0.6} \\
\hline & $2000-5000$ LE & 40 & $3215.7+1128.2$ & \\
\hline & $>5000 \mathrm{LE}$ & 17 & $3454.2+1651.8$ & \\
\hline \multirow{4}{*}{ Economic status } & In debt & 7 & $3327.7+920.8$ & \multirow[t]{4}{*}{0.5} \\
\hline & $\begin{array}{l}\text { Just meet routine } \\
\text { expenses }\end{array}$ & 19 & $3185.0+1023.0$ & \\
\hline & $\begin{array}{lr}\text { Meet routire } \\
\text { expenses } \quad \text { and } \\
\text { emergencies }\end{array}$ & 26 & $2901.0+1383.5$ & \\
\hline & $\begin{array}{l}\text { Able to save or } \\
\text { invest }\end{array}$ & 44 & $3379.4 \pm 1369.3$ & \\
\hline
\end{tabular}

Correlation is significant difference at $p<0.05$ 
Sahar S. Zaghloul Ashraf A. Abd-El Mogeid

Asmaa S. Abd ElAal, Naglaa M. Abd El Fattah,

Table 2: Mean \pm SD sodium intake $(\mathrm{mg})$ by meał

\begin{tabular}{l|c|c}
\hline Meal & $N$ & Sodium \pm SD(mg) \\
\hline Breakfast & 96 & $1987.1 \pm 1251.1$ \\
\hline Morning Snack & 74 & $230.5 \pm 317.5$ \\
\hline Lunch & 94 & $2726.4 \pm 1406.9$ \\
\hline Afternoon Snack & 60 & $133.1 \pm 280.2$ \\
\hline Dinner & 88 & $1612.8 \pm 1439.1$ \\
\hline Evening Snack & 18 & $102.1+168.2$ \\
\hline
\end{tabular}


Egyptian J. of Nutrition Vol. XXXIII No. 3 (2018)
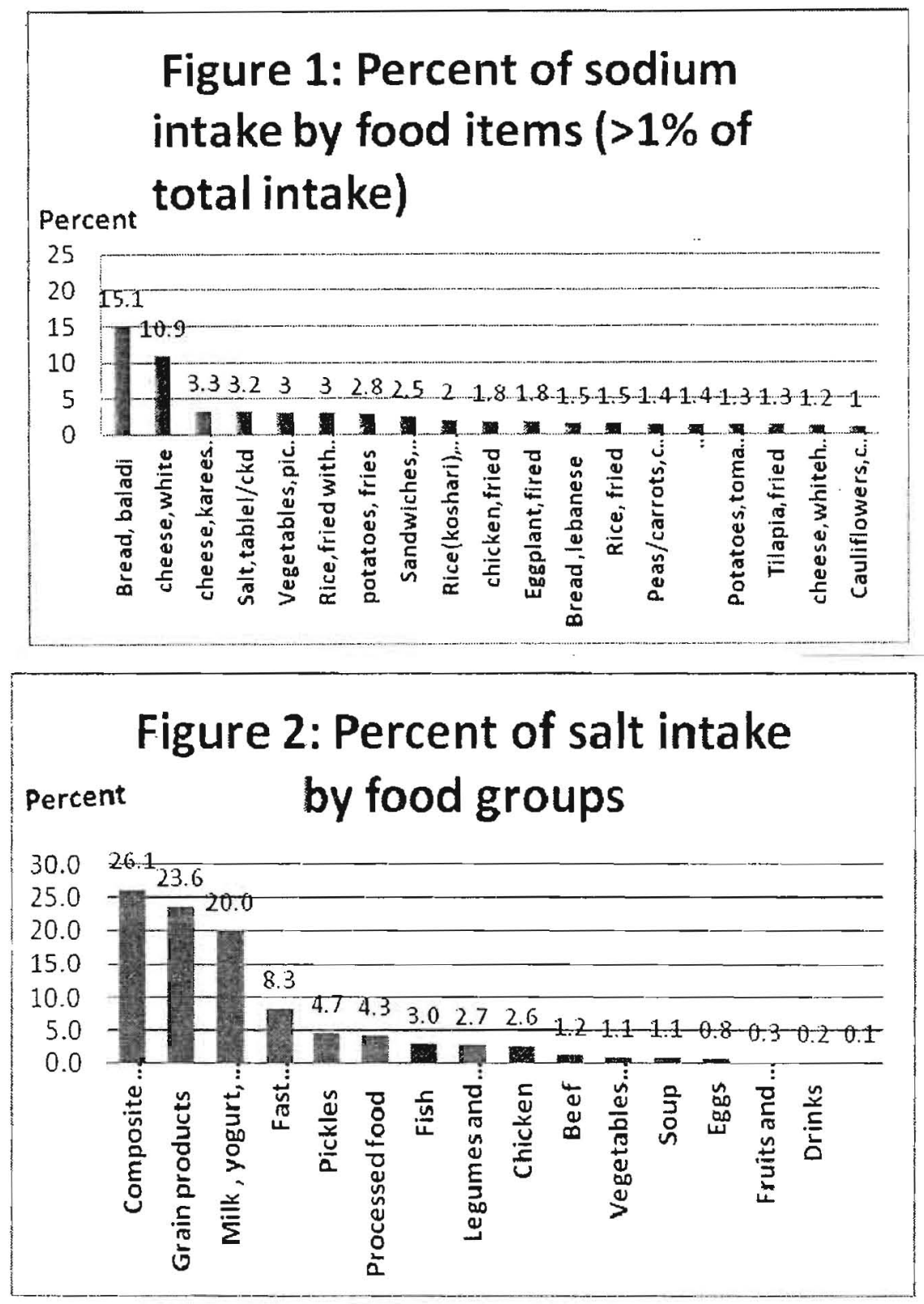
Sahar S. Zaghloul Ashraf A. Abd-El Mogeid

Asmaa S. Abd ElAal, Naglaa M. Abd El Fattah,

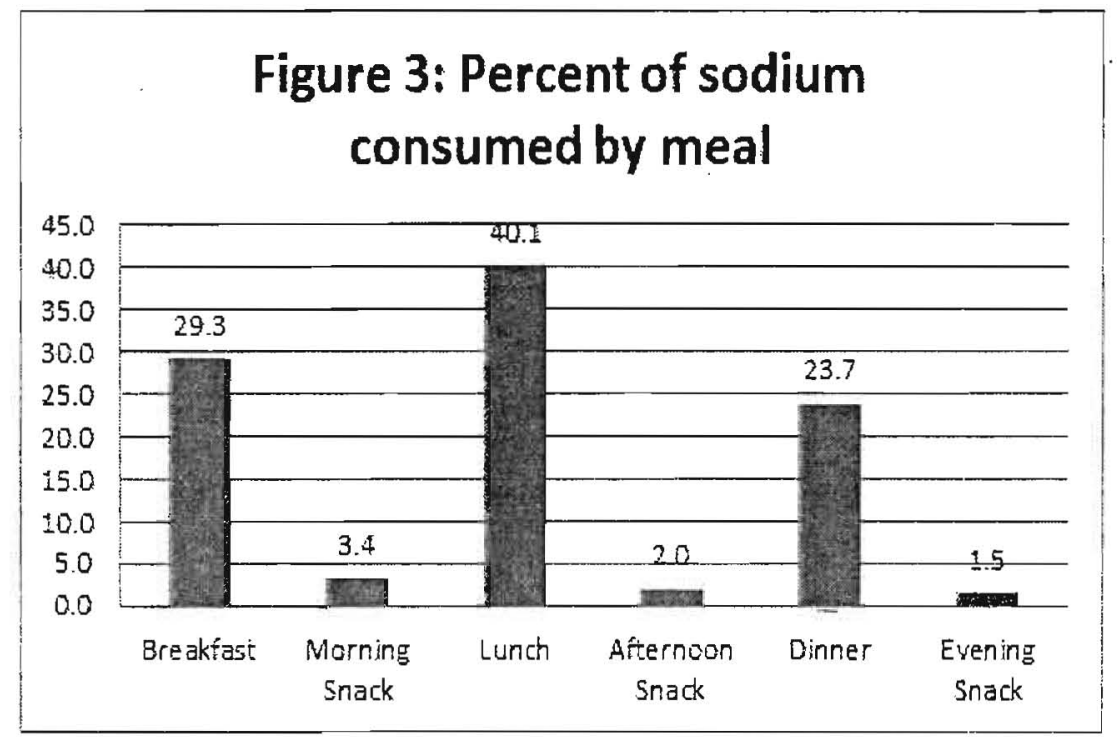


Egyptian J. of Nutrition Vol. XXXIII No. 3 (2018)

\section{References}

Abd El Aal A, Abdul Aziz A, Zaghloul SS. (2018):

Construct validity of 24 hour recall estimating accuracy of energy and sodium Intake. Egyptian J. of Nutrition, 33(2):128.

Adler, A. J., Taylor, F.; Martin, N., Gottlieb, S.,Taylor, R. S., and Ebrahim, S.(2014):

Reduced dietary salt for the prevention of cardiovascular disease. Cochrane Database Syst Rev, 12 (12).

Al Medawar, M.M., Nasreddine, L., Olabi, A., Hamade, H., Awad, E., Toufeili, I., Arnaout, S.andlsma'eel, H.A.(2015):

Sodium intake reduction efforts in Lebanon. Cardiovasc DiagTher, 5(3):178-185. doi: 10.3978/j.issn.22233652.2015.04.09

Anderson, C. A. M., Appel, L. J., Okuda, N., Brown, I. J., Chan, Q., Zhao, L., Ueshima, H., Kesteloot, H., Miura, K. and Curb, J. D. (2010):

Dietary sources of sodium in China, Japan, the United Kingdom, and the United States, women and men aged 40 to 59 years: The INTERMAP study. J. Am. Diet. Assoc. $110,736-745$.

Charlton, K., Yeatman, H. and Houweling, F. (2010):

Urinary sodium excretion, dietary sources of sodium intake and knowledge and practices around salt use in a group of healthy Australian women.Aust $\mathrm{N} Z \mathrm{~J}$ Public Health 34,356-363.

Eid, N. (2006).

Food composition tables for Egypt National Nutrition Institute Cairo, A.R.E. second

Edition May, 2006. 
Sahar S. Zaghloul Ashraf A. Abd-EI Mogeid

Asmaa S. Abd ElAal, Naglaa M. Abd El Fattah,

Erdem,Y.,Akpolat, T.,Derici, Ü.,Sengül, S.,Ertürk, S.,Ulusoy ,S.,Altun, B. and AriciN, M. (2017): Dietary Sources of High Sodium Intake in Turkey: SALTURK II Nutrients, 9.(9)933, doi: $10.3390 /$ nu909093.

European Food Safety Authority (2016):

"EFSA provides advice on adverse effects of sodium".https://www, efsa. europa.eu/en/press/news/05062 2

Fischer P. W.F., Vigneault, M.P.(2009):

Sodium food Sources in the Canadian diet. Applied Physiology, Nutrition, and Metabolism, 34(5): 884892, https://doi.org/10.1139/H09-077

Food Standards Australia and New Zealand(2015) AUSNUT(2011-2013) :

http://www foodstandards.gov.au/science/monitor ingnutrients/ausnut/ Pages/about. as.

Graudal, N. A., Hubeck-Graudal, T. and Jurgens, G. (2011): "Effects of low sodium diet versus high sodium diet on blood pressure, renin, aldosterone, catecholamines, cholesterol, and triglyceride". The Cochrane Database of Systematic Reviews (11): CD004022. doi:10.1002/14651858.CD004022.pub3. PMID 22071811

Hasenegger,V., Rust,P.,König, J.,Purtscher,A.,Erler, J. and Ekmekcioglu, C. (2018):

Main Sources, Socio-Demographic and Anthropometric Correlates of Salt Intake in Austria.Nutrients. 10(3): 311. 
He, F. J., Li, J., Macgregor, G. A. (2013):

Effect of longer term modest salt reduction on blood pressure: Cochrane systematic review and meta-analysis of randomized trials". BMJ (Clinical research ed.). 346: f1325. doi: 10. 1136/bmj.f1325. PMID 23558162.

He, F.J.; Pombo-Rodrigues, S. and Macgregor, G.A. (2014):

Salt reduction in England from 2003 to 2011: its relationship to blood pressure, stroke and ischemic heart disease mortality. BMJ Open, 4(4), e004549. http://doi.org/10.1136/bmjopen-2013-004549

Institute of Medicine (IOM), (2013):

Sodium intake in populations: Assessment of Evidence. Washington, DC: The National Academies Press. https://doi.org/10.17226/18311

James, W.; Ralph, A. and Sancez-Castillo, C. (1987): The dominance of salt in manufactured food in the sodium intake of affluent societies. Lancet, 426-429.

Keogh, J.B.; Lange, K.; Hogarth, R. and Clifton, P.M.(2013):

Foods contributing to sodium intake and urinary sodium Excretion in a group of Australian women. Public Health Nutrition: $16(10), 1837-1842$

Khan, M.A. (1983):

Sodium intake from meals and snacks consumed by college students. J Am Diet Assoc. 82(6):664-6.

Kochanek, K.D.; Xu, J.Q.; Murphy, S.L.; Miniño, A.M.And Kung, H.C. (2011):

Deaths: final data for 2009.Centers for Disease Control and Prevention Nat Vital Stat Rep. 60 (3). 
Sahar S. Zaghloul Ashraf A. Abd-El Mogeid

Asmaa S. Abd ElAal, Naglaa M. Abd El Fattah,

Mattes RD and Donnelly D. (1991):

Relative contributions of dietary sodium sources. . Centers for Disease Control and Prevention J Am CollNutr. 10:38393.

Margerison, C., Nowson, C.A. and Worsley, T. (2004):

Food sources of sodium prior to and during the OZDASH study. Asia Pac J Clin Nutr 13,supl.s 58.

Moshfegh, A.J., Rhodes, D.G., Baer, D.J.,Murayi, T., Clemens, J.C.,Rumpler, W.V., Paul, D.R.,Sebastian, R.S.,Kuczynski, K.J. and Ingwersen, L.A .(2008):

The US Department of Agriculture automated MultiplePass Method reduces bias in the collection of energy intakes. Am J Clin Nutr, 88:324- 32.

Russell, D., Parnell, W., Wilson, N., et al (1999):

NZ Food: NZ People. Key results of the 1997 National Nutrition Survey. Wellington: Ministry of Health. https://researchspace.auckland. ac.nz/handle/2292/34830 (accessed August 2018)

Shim E.; Ryu, H.J., Hwang, J., Kim, S.Y. and Chung, E.J.(2013):

Dietary sodium intake in young Korean adults and its relationship with eating frequency and taste preference.Nutr Res Pract. 7(3):192-8

Song, D.Y., Park, J. E., Shim, J E. and Lee J. E. (2013):

Trends in the major dish groups and food groups contributing to sodium intake in the Korea National Health and Nutrition Examination Survey 1998-2010 Korean J Nutr. $46(1): 72-85$

Strazzullo, P., and Leclercq, C. (2014):

Sodium. Advances in Nutrition, 5(2), 188190.http://doi.org/10.3945/an.113.005215 
Egyptian J. of Nutrition Vol. XXXIII No. 3 (2018)

Whelton PK, Appel LJ, Sacco RL, Anderson CA, Antman EM, Campbell N, Dunbar SB, Frohlich ED, Hall JE, Jessup M, LabartheDR, MacGregor GA, Sacks FM, Stamler J, Vafiadis DK, Van Horn LV.(2012):

Sodium, blood pressure, and cardiovascular disease: further evidence supporting the American Heart Association sodium reduction recommendations. Circulation;126 2880-9.

World Health Organization WHO (1995):

Physical status: the use and interpretation of anthropometry. Report of a WHO Expert Committee. Technical Report Series No. 854. Geneva: World Health Organization

World Health Organization. (2014):

Global status report on non-communicable diseases 2010. [Cited $2014 \quad 30$ September]. available: http://whqlibdoc. who. int/publications/2011/978924068645 8_eng.pdf?ua=1

Zhao L, Stamler J, Yan LL, Zhou B, Wu Y, Liu K, Davigius ML, Dennis BH, Elliott P, Ueshima H, Yang J, Zhu L, Guo D, INTERMAP Research Group (2004).

Blood pressure differences between northern and southern Chinese: Role of dietary factors: The International study on macronutrients and blood pressure. Hypertension, 43 (6): 1332-1337. 
Sahar S. Zaghloul Ashraf A. Abd-El Mogeid

Asmaa S. Abd ElAal, Naglaa M. Abd El Fattah,

مصادر الصوديوم الغذائي بين البالغين المصريين.

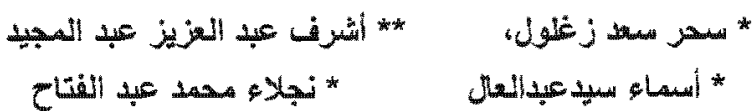

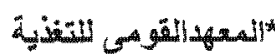

* * كلية|لاقتصادالمنزني - جامعة حلوان

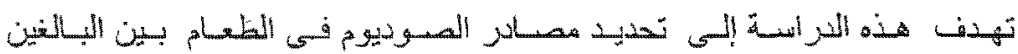

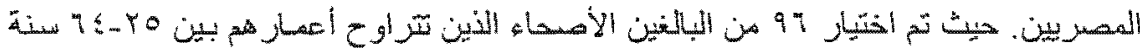

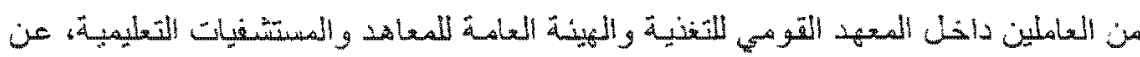

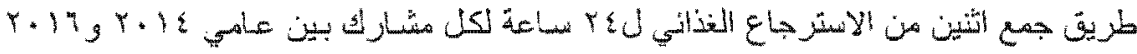

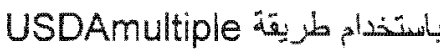
وكتلك تم قياس اللوزت والطول بالإضافة إلى جمع البيانات Pass method

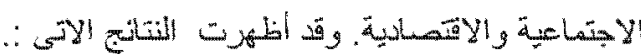

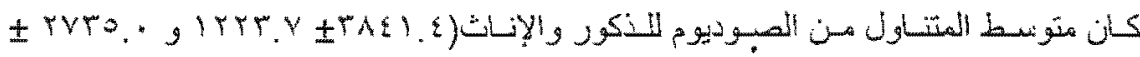
11119.9

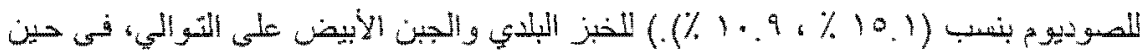

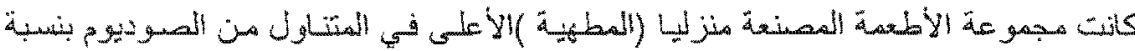

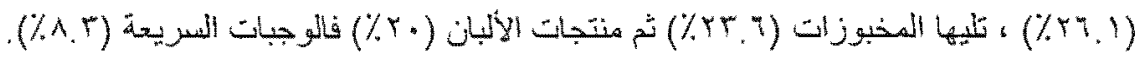

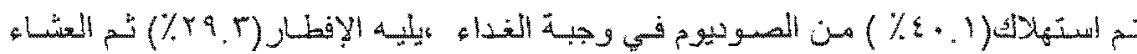

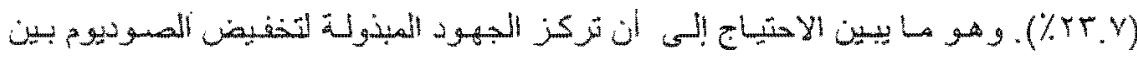

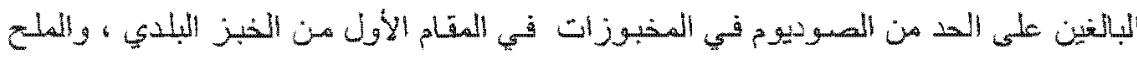

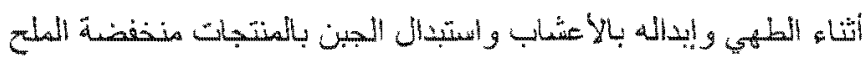

